\title{
Perbandingan Kombinasi Tramadol Parasetamol Intravena dengan Tramadol Ketorolak Intravena terhadap Nilai Numeric Rating Scale dan Kebutuhan Opioid Pascahisterektomi
}

\author{
Dendi Karmena, ${ }^{1}$ Ezra Oktaliansah, ${ }^{2}$ Eri Surahman ${ }^{2}$ \\ ${ }^{1}$ Rumah Sakit Umum Daerah Teluk Kuantan, ${ }^{2}$ Departemen Anestesiologi dan Terapi intensif \\ Fakultas Kedokteran Universitas Padjadjaran/Rumah Sakit Dr. Hasan Sadikin Bandung
}

\begin{abstract}
Abstrak
Nyeri pascabedah adalah masalah penting dalam pembedahan. Penelitian ini bertujuan membandingkan kombinasi tramadol parasetamol intravena dengan tramadol ketorolak intravena terhadap nilai numeric rating scale (NRS) dan kebutuhan opioid pascabedah histerektomi abdominal. Uji klinik acak terkontrol buta ganda dilakukan terhadap 42 wanita (18-60 tahun) status fisik American Society of Anesthesiologist (ASA) I-II yang menjalani pembedahan histerektomi abdominal dalam anestesi umum di Rumah Sakit Dr. Hasan Sadikin Bandung pada bulan Agustus-November 2014. Pasien dibagi menjadi dua kelompok, yaitu 21 orang menerima kombinasi tramadol parasetamol intravena dan 21 orang menerima kombinasi tramadol ketorolak intravena yang diberikan saat dilakukan penutupan peritoneum. Penilaian skala nyeri dilakukan dengan menggunakan nilai numeric rating scale baik pada saat istirahat maupun saat mobilisasi. Analisis menggunakan Uji Mann-Whitney. Pada penelitian ini ditemukan nilai NRS pada kelompok tramadol parasetamol dan kelompok tramadol ketorolak tidak berbeda bermakna ( $>0,05)$. Simpulan penelitian ini adalah pemberian kombinasi tramadol parasetamol intravena sebanding dengan kombinasi tramadol ketorolak terhadap nilai NRS dan kebutuhan opioid pascabedah histerektomi abdominal.
\end{abstract}

Kata kunci: Kebutuhan opioid, ketorolak, numeric rating scale, parasetamol, tramadol

\section{Comparison of Combined Intravenous Tramadol-Paracetamol Versus Tramadol-Ketorolac on Numeric Rating Scale and Opioid Requirement on Post Histerectomy Patients}

\begin{abstract}
Postoperative pain is an important problem in surgery. This study aimed to compare the combination of intravenous tramadol paracetamol and tramadol ketorolac to numeric rating scale (NRS) to postoperative opioid requirements in abdominal hysterectomy. Double blind randomized controlled trial was conducted on 42 women (18-60 years) with ASA physical status I-II who underwent abdominal hysterectomy surgery under general anesthesia in Dr. Hasan Sadikin General Hospital Bandung within the period of AugustNovember 2014. Subjects were divided into two groups: 21 subjects received a combination of intravenous tramadol paracetamol and 21 subjects received combination of intravenous tramadol ketorolac that was given when peritoneum was closure. The assessment of postoperative pain was performed using a numeric rating scale both at rest and during mobilization. Correlation analysis is conducted using Mann-whitney test. Result shows that the value of the NRS in group tramadol paracetamol compared to tramadol ketorolac was not significantly different ( $p>0.05$ ). This study concludes that the combinations of intravenous tramadol paracetamol and tramadol ketorolac are the same in terms of the NRS and postoperative opioid requirement after abdominal hysterectomy.
\end{abstract}

Key words: Ketorolac, numeric rating scale, opioid requirement, paracetamol, tramadol

Korespondensi: Dendi Karmena, dr., SpAn, Rumah SakitUmum Daerah Teluk Kuantan, Jl. Kesehatan No.1 Teluk Kuantan, Mobile 085265248862, Email dendikarmena@yahoo.co.id 


\section{Pendahuluan}

Nyeri pascabedah masih menjadi masalah utama yang dihadapi ahli anestesi. Hal tersebut merupakan salah satu masalah pembedahan paling ditakuti oleh pasien. Nyeri pascabedah merupakan suatu reaksi fisiologis kompleks terhadap kerusakan jaringan ataupun respons pada penyakit yang dirasakan pasien sebagai suatu pengalaman sensoris dan juga emosional yang tidak menyenangkan. Penanganan nyeri yang tidak adekuat akan menyebabkan efek samping fisiologis yang akan meningkatkan morbiditas dan mortalitas, juga menghambat proses penyembuhan. ${ }^{1-3}$

Prosedur pembedahan abdomen termasuk juga pembedahan ginekologi merupakan salah satu jenis pembedahan yang mengakibatkan intensitas nyeri pascabedah yang cukup tinggi sehingga perhatian lebih serius dibutuhkan untukmengatasi nyeri pascabedah yang terjadi. Nyeri pascabedah histerektomi abdominal termasuk nyeri hebat. Penilaian nyeri dapat dilakukan secara subjektif memakai beberapa macam skala, skala untuk nyeri histerektomi adalah 7 hingga $8 .^{4}$

Penanganan nyeri dapat dilakukan secara farmakologis dengan menggunakan analgetik dan nonfarmakologis melalui teknik mekanis, elektris, serta psikologis. Sampai saat ini para ahli masih terus mencari jenis analgetik yang lebih baik dengan efek samping yang minimal, aman, dan mudah untuk digunakan.,5

Opioid merupakan analgetik pilihan yang utama untuk mengatasi nyeri sedang sampai berat. Akan tetapi, opioid memiliki berbagai keterbatasan antara lain adalah efek samping yang mungkin timbul, seperti depresi napas, mengantuk, menurunkan motilitas saluran cerna, mual dan muntah, dan juga berpotensi disalahgunakan. Akibat efek samping opioid tersebut, para peneliti terus mengembangkan cara pemberian analgetik secara multimodal untuk mengurangi dosis opioid pascabedah. ${ }^{5}$

Penggunaan terapi multimodal membuat skor nyeri lebih rendah, mempercepat masa pemulihan, meningkatkan kepuasan pasien, serta mengurangi lama perawatan di rumah sakit. $^{6}$
Saat ini analgesia multimodal pascabedah banyak memakai opioid yang dikombinasikan dengan obat lain, di antaranya non-steroidal anti-inflammatory drug (NSAID), parasetamol, ketamin dosis rendah, dan pemberian anestesi lokal perioperatif. ${ }^{6,7}$

Tramadol merupakan analgetik opioid yang diindikasikan untuk mengobati nyeri sedang sampai berat, baik yang bersifat akut maupun kronik. Lebih dari 90 negara di dunia telah memakai obat ini sebagai analgetik, namun penggunaan tramadol juga mengakibatkan efek samping, antara lain adalah depresi napas, mengantuk, mual muntah, dan menyebabkan ketergantungan. ${ }^{8}$

Ketorolak merupakan salah satu NSAID yang sering digunakan dalam mengatasi nyeri pascabedah karena memiliki efek analgesia yang kuat serta efek anti-inflamasi. Ketorolak juga sama efektif dengan morfin dan petidin yang dapat mencegah nyeri akut pascabedah dari tingkat nyeri sedang sampai dengan berat tanpa menyebabkan depresi pada pernapasan. Pemberian ketorolak juga harus diwaspadai karena berkaitan dengan peningkatan risiko perdarahan pada daerah pembedahan yang disebabkan oleh waktu perdarahan meningkat, perdarahan gastrointestinal, dispepsia, dan juga menyebabkan gangguan ginjal. Ketorolak juga masih memiliki efek samping lain seperti mual, nyeri kepala, mengantuk, palpitasi, dan pruritus. ${ }^{9}$

Parasetamol adalah analgetik nonopioid dan nonsalisilat yang sudah digunakan lebih dari 40 tahun untuk mengatasi nyeri ringan sampai sedang. Parasetamol bekerja dengan meningkatkan batas ambang nyeri dengan cara menghambat $N$-metil-D-aspartate (NMDA) atau disebut substansi $P$ serta prostaglandin $E_{2}$ di sentral. Parasetamol memiliki efek analgesia dan juga antipiretik tanpa efek anti-inflamasi, aman digunakan, efek samping minimal, dan ditoleransi dengan baik. ${ }^{10,11}$

Parasetamol juga memiliki efek opioidsparing bila digunakan bersama dengan opioid dosis yang rendah sehingga memberikan efek analgesia yang baik dengan meminimalkan efek samping opioid seperti depresi napas, bradikardia, dan hipoksia. ${ }^{10,11}$ 
Tramadol intravena merupakan salah satu analgetik opioid yang sering dipergunakan di Rumah Sakit Dr. Hasan Sadikin (RSHS)Bandung karena mudah didapatkan serta efektif untuk mengatasi rasa nyeri pascabedah. Penggunaan tramadol ini sering kali dikombinasikan untuk mengatasi nyeri sedang sampai berat dengan analgetik lain terutama ketorolak intravena. Analgetik lainnya yang sering dipakai adalah parasetamol intravena.

Penelitian ini bertujuan membandingkan pemberian kombinasi tramadol-parasetamol 1 g intravena dengan tramadol-ketorolak $30 \mathrm{mg}$ intravena terhadap nilai numeric rating scale dan juga jumlah kebutuhan opioid pascabedah histerektomi abdominal.

\section{Subjek dan Metode}

Penelitian ini berrsifat eksperimental dengan uji acak terkontrol buta ganda (double blind randomized controlled trial). Pemilihan subjek penelitian berdasar atas kriteria inklusi yaitu semua pasien yang dirawat di Rumah Sakit Dr. Hasan Sadikin (RSHS) Bandung yang menjalani pembedahan histerektomi abdominal elektif dengan anestesia umum, status fisik American Society of Anesthesiologists (ASA) I-II, serta berusia 18-60 tahun. Kriteria eksklusi adalah riwayat alergi dan kontraindikasi terhadap obat-obatan yang digunakan dalam penelitian, sedang mendapat terapi analgetik sebelumnya (opioid, parasetamol, NSAID), riwayat nyeri kronik, pusing, atau nyeri kepala berulang.

Besarnya sampel ditentukan berdasarkan formula uji hipotesis dua rata-rata. Didapatkan jumlah sampel adalah 21 untuk tiap kelompok perlakuan. Analisis statistika terhadap hasil penelitian menggunakan uji-t, uji chi kuadrat, dan juga Uji Mann-Whitney. Data disajikan dan dianalisis mempergunakan statistical product and service solutions (SPSS) 20.0 for windows.

Setelah mendapat persetujuan dari Komite Etik Penelitian Kesehatan Fakultas Kedokteran Unpad/RSHS Bandung, dilakukan kunjungan prabedah satu hari sebelum operasi dan juga diberikan penjelasan mengenai penelitian dan menandatangani surat persetujuan (informed consent) mengenai operasi dan juga penelitian yang akan dilaksanakan, serta dijelaskan pula cara penilaian NRS.

Semua penderita dipuasakan selama enam jam sebelum operasi dari makanan padat dan dua jam dari air bening. Randomisasi sampel dilakukan dengan menggunakan tabel bilangan random, kemudian sampel dibagi menjadi dua kelompok, yaitu kelompok PI (parasetamol infus $1 \mathrm{~g}$ ) dan KI (ketorolak intravena $30 \mathrm{mg}$ ). Semua kelompok mendapatkan premedikasi dengan lorazepam 1,0 mg pada malam hari.

Pasien dibaringkan terlentang di ruang operasi, dilakukan pemasangan alat pantau dan dicatat data mengenai kesadaran, tekanan darah, laju nadi, laju napas, dan juga saturasi oksigen. Selanjutnya, dilakukan pemasangan kateter intravena serta diberikan cairan infus Ringer laktat (RL) untuk menggantikan puasa.

Induksi anestesia dilakukan dengan cara memberikan propofol $2 \mathrm{mg} / \mathrm{kgBB}$, fentanil 2 $\mu \mathrm{g} / \mathrm{kgBB}$, atrakurium 0,5 mg/kgBB, dan setelah tiga menit kemudian dilakukan laringoskopiintubasi. Pemeliharaan anestesia dilakukan dengan memakai isofluran dan $\mathrm{N}_{2} \mathrm{O}: \mathrm{O}_{2} 50 \%$. Saat peritoneum mulai ditutup diberikan bolus intravena tramadol $1 \mathrm{mg} / \mathrm{kgBB}$. Kemudian, pasien kelompok KI diberikan ketorolak $30 \mathrm{mg}$ intravena, sedangkan kelompok PI diberikan parasetamol infus $1 \mathrm{~g}$.

Pada saat akhir operasi diberikan antagonis pelumpuh otot menggunakan neostigmin dosis 0,04-0,08 mg/kgBB dan sulfas atropin dosis 0,01-0,04 mg/kgBB intravena. Pencegahan mual muntah diberikan ondansetron $0,05 \mathrm{mg} /$ kgBB secara intravena. Selanjutnya, analgetik pascabedah menggunakan tramadol $2 \mathrm{mg} /$ kgBB yang diberikan secara drip intravena selama $8 \mathrm{jam}$. Dosis analgetik pascabedah yang sama diberikan sampai 24 jam pascabedah.

Setelah diekstubasi, kemudian dipindahkan ke ruang pemulihan dan dilakukan observasi selama 24 jam. Penilaian nyeri pascabedah dilakukan menggunakan NRS pada menit ke30, jam ke-1, 2, 4, 6, 8, 16, dan 24 pascabedah. Pencatatan skor nyeri, laju nadi, tekanan darah, laju napas, efek samping obat, penggunaan petidin tambahan, dan juga penggunaan total petidin dilakukan selama 24 jam. Nilai NRS lebih dari 3 diberikan analgetik 
Tabel 1 Karakteristik Umum Subjek Penelitian Kedua Kelompok Perlakuan

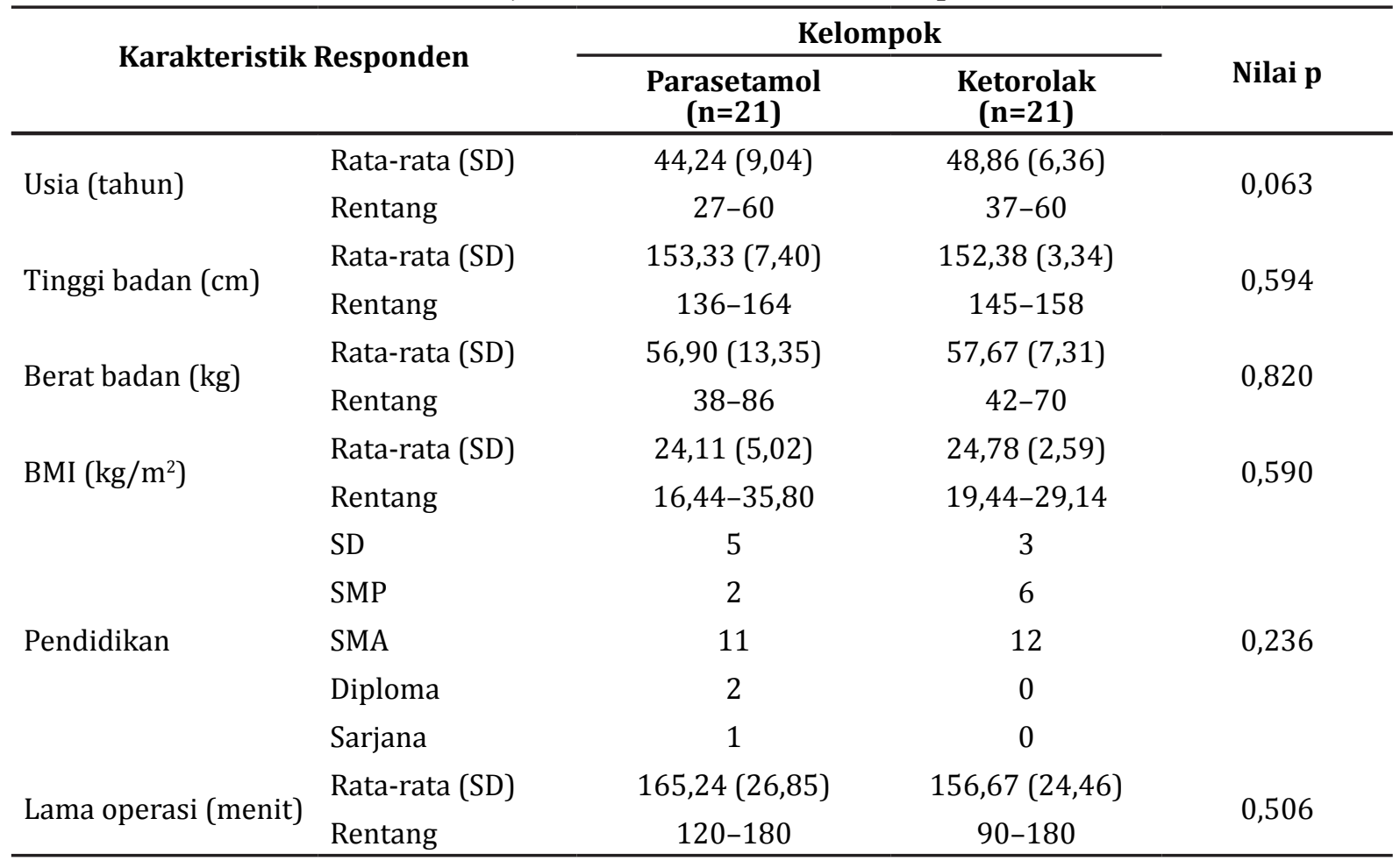

Keterangan: nilai p pada variabel lama operasi dihitung berdasarkan Uji Mann-Whitney. Nilai p dihitung

penyelamatan dengan petidin $0,5 \mathrm{mg} / \mathrm{kgBB}$. Bila nilai NRS masih lebih dari 3 maka 15 menit kemudian dapat diberikan kembali analgetik pertolongan. Pemberian petidin dihentikan bila laju napas $<12 x /$ menit atau timbul efek samping serius akibat pemakaian petidin.

\section{Hasil}

Hasil analisis statistika menunjukkan bahwa untuk variabel usia, tinggi badan, berat badan, body mass index (BMI), pendidikan, dan lama operasi pada kedua kelompok perlakuan tidak berbeda bermakna ( $p>0,05$; Tabel 1). Rentang

Tabel 2 Perbandingan Nilai NRS Saat Istirahat antara Kedua Kelompok

\begin{tabular}{|c|c|c|c|c|c|}
\hline \multirow{3}{*}{ Waktu Pengukuran } & \multicolumn{4}{|c|}{ Kelompok } & \multirow{3}{*}{ Nilai p } \\
\hline & \multicolumn{2}{|c|}{ Parasetamol $(\mathrm{n}=21)$} & \multicolumn{2}{|c|}{ Ketorolak (n=21) } & \\
\hline & Modus & Rentang & Modus & Rentang & \\
\hline Т $1 / 2$ & 1 & $0-3$ & 1 & $0-3$ & 0,254 \\
\hline Т 1 & 2 & $1-3$ & 2 & $1-3$ & 0,651 \\
\hline Т 2 & 2 & $1-3$ & 2 & $1-2$ & 0,946 \\
\hline T 4 & 2 & $1-3$ & 2 & $1-3$ & 0,962 \\
\hline T 6 & 2 & $1-3$ & 2 & $1-2$ & 0,592 \\
\hline T 8 & 2 & $1-3$ & 2 & $1-2$ & 0,965 \\
\hline T 16 & 2 & $1-3$ & 2 & $1-2$ & 0,178 \\
\hline T 24 & 1 & $1-2$ & 2 & $1-2$ & $0,012^{*}$ \\
\hline
\end{tabular}

Keterangan: T1=jam ke-1, $\mathrm{T}_{2}=$ jam ke-2, dan seterusnya. ${ }^{*}$ Nilai $\mathrm{p}$ bermakna jika $(\mathrm{p}<0,05)$ 
Tabel 3 Perbandingan Nilai NRS Saat Mobilisasi antara Kedua Kelompok

\begin{tabular}{|c|c|c|c|c|c|}
\hline \multirow{3}{*}{ Waktu Pengukuran } & \multicolumn{4}{|c|}{ Kelompok } & \multirow{3}{*}{ Nilai p } \\
\hline & \multicolumn{2}{|c|}{ Parasetamol $(n=21)$} & \multicolumn{2}{|c|}{ Ketorolak $(n=21)$} & \\
\hline & Modus & Rentang & Rata-rata & Rentang & \\
\hline $\mathrm{T} 1 / 2$ & 2 & $1-4$ & 2 & $1-4$ & $0,023^{*}$ \\
\hline Т 1 & 2 & $1-4$ & 2 & $1-3$ & 0,331 \\
\hline Т 2 & 2 & $1-3$ & 2 & $1-2$ & 0,269 \\
\hline $\mathrm{T} 4$ & 2 & $1-3$ & 2 & $1-3$ & 0,752 \\
\hline T 6 & 2 & $1-3$ & 2 & $1-3$ & 0,325 \\
\hline T 8 & 2 & $1-3$ & 2 & $1-2$ & 0,456 \\
\hline Т 16 & 2 & $1-3$ & 2 & $1-2$ & 0,681 \\
\hline Т 24 & 2 & $1-2$ & 2 & $1-2$ & $0,043^{*}$ \\
\hline
\end{tabular}

Keterangan: T1=jam ke-1, T2=jam ke-2, dan seterusnya. * Nilai p bermakna jika $(p<0,05)$

nilai NRS saat istirahat, baik pada kelompok tramadol-parasetamol $1 \mathrm{~g}$ intravena maupun kelompok tramadol-ketorolak 30 mg intravena didapatkan antara 0 sampai 3 . Berdasar atas pengujian statistika, diketahui bahwa nilai NRS saat istirahat pada menit ke-30, jam ke-1, 2, 4, 6, 8, dan 16 pascabedah pada kedua kelompok perlakuan tidak berbeda bermakna $(p>0,05)$, sedangkan pada jam ke-24 pascabedah pada kedua kelompok perlakuan berbeda bermakna ( $\mathrm{p}<0,05$; Tabel 2).

Rentang nilai NRS saat mobilisasi pada kelompok tramadol parasetamol $1 \mathrm{~g}$ intravena secara keseluruhan didapatkan nilai 1-4 dan pada kelompok tramadol ketorolak $30 \mathrm{mg}$ intravena didapatkan 0-4. Berdasarkan hasil analisis statistika menunjukkan bahwa untuk NRS mobilisasi, pada jam ke-1, 2, 4, 6, 8, dan jam ke-16 pascabedah pada kedua kelompok perlakuan tidak berbeda bermakna $(p>0,05)$, sedangkan pada menit ke-30 dan jam ke-24 pascabedah pada kedua kelompok perlakuan berbeda bermakna $(p<0,05$; Tabel 3).

Berdasar atas hasil penelitian ini diketahui bahwa pada kedua kelompok mayoritas tidak diberikan tambahan analgetik. Pada kelompok tramadol parasetamol 1 gram intravena hanya 3 orang yang diberikan tambahan analgetik, sedangkan pada kelompok tramadol ketorolak $30 \mathrm{mg}$ intravena hanya seorang yang diberikan tambahan analgetik. Hasil statistik tambahan analgetik menunjukkan pada kedua kelompok perlakuan tidak berbeda bermakna $(p>0,05)$.

Subjek penelitian pada kelompok tramadol parasetamol $1 \mathrm{~g}$ intravena mengalami efek samping pusing sebanyak 1 subjek, mengantuk 3 subjek, mual 6 subjek, dan juga menggigil 3 subjek. Pada kelompok tramadol ketorolak 30 mg intravena, efek samping mengantuk terjadi pada 5 subjek, mual 3 subjek, dan menggigil 1

Tabel 4 Perbandingan Efek Samping antara Kedua Kelompok

\begin{tabular}{lccc}
\hline \multirow{2}{*}{ Efek Samping } & \multicolumn{2}{c}{ Kelompok } & \multirow{2}{*}{ Nilai p } \\
\cline { 2 - 3 } & Parasetamol (n=21) & Ketorolak (n=21) & \\
\hline Pusing & 1 & 0 & \\
Mual & 6 & 3 & 0,367 \\
Muntah & 0 & 0 & \\
Mengantuk & 3 & 5 & \\
Menggigil & 3 & 1 & \\
\hline
\end{tabular}

Keterangan: nilai $p$ dihitung berdasarkan uji chi-kuadrat. Nilai p bermakna jika $(p<0,05)$ 
subjek. Hasil analisis statistika menunjukkan bahwa efek samping yang terjadi pada kedua kelompok perlakuan tidak berbeda bermakna ( $p>0,05$; Tabel 4).

\section{Pembahasan}

Tujuan utama penanganan nyeri pascabedah adalah memulihkan fungsi organ secara cepat dan juga menghindari komplikasi. Penanganan nyeri yang baik akan mengurangi morbiditas serta komplikasi pascabedah, meningkatkan kenyamanan dan kepuasan pasien, mobilisasi lebih dini, mempercepat penyembuhan, serta mengurangi biaya perawatan rumah sakit.,

Dalam penelitian ini, hasil analisis statistika menunjukkan variabel usia, tinggi badan, berat badan, body mass index (BMI), pendidikan, dan lama operasi pada kedua kelompok perlakuan tidak berbeda bermakna sehingga subjek yang diteliti homogen dan layak dibandingkan.

Pemberian kombinasi analgetika tramadolparasetamol 1 gram intravena serta tramadolketorolak $30 \mathrm{mg}$ intravena bertujuan untuk mendapatkan efek analgesi yang maksimal. Efek analgetik pada kedua kelompok dalam mengatasi nyeri sedang sampai berat selama 24 jam pascabedah histerektomi berdasar uji statistika menunjukkan hasil yang sebanding antara kedua kelompok.

Penilaian nyeri pascabedah dengan NRS menunjukkan bahwa pada kelompok tramadol parasetamol 1 gram intravena serta tramadol ketorolak 30 mg i.v. mempunyai rentang nilai NRS 0 sampai 3 pada saatistirahat serta rentang yang sama dengan skala 1-4 saat mobilisasi. Setelah dilakukan Uji Mann-Whitney antara kedua kelompok tidak ditemukan perbedaan nilai NRS yang bermakna secara statistik pada 6 waktu pengukuran. Pada menit ke-30 serta jam ke-24 ditemukan nilai NRS yang bermakna pada 2 waktu pengukuran, namun masih berada dalam rentang yang sama dan tidak memengaruhi pemakaian analgetik tambahan.

Dilihat secara keseluruhan dari delapan waktu pengukuran tidak terdapat perbedaan bermakna terhadap pengukuran NRS, baik saat istirahat maupun saat mobilisasi antara kedua kelompok perlakuan. Hal ini juga dikuatkan dengan suatu penilaian kebutuhan analgetik pertolongan yang diberikan, yaitu pada 3 dari 21 orang dari kelompok tramadol parasetamol dan 1 dari 21 orang dari kelompok tramadol ketorolak. Penilaian terhadap jumlah analgetik pertolongan secara klinis terlihat bahwa kombinasi tramadol-parasetamol mempunyai efek analgetik lebih lemah dibanding dengan tramadol-ketorolak, namun secara statistika tidak terdapat perbedaan bermakna antara kelompok tramadol parasetamol dan tramadol ketorolak.

Penilaian NRS serta tambahan kebutuhan analgetik dikatakan sebanding antara kedua kelompok ini, walaupun terdapat perbedaan cara kerja antara parasetamol dan ketorolak. Kelebihan parasetamol bekerja di sentral dan perifer, sedangkan ketorolak bekerja hanya di perifer. Namun, parasetamol tidak mempunyai efek anti-inflamasi seperti efek yang dimiliki oleh ketorolak. Parasetamol dan juga ketorolak mempunyai efek farmakokinetik yang sama terutama dilihat dari onset dan durasi kedua obat tersebut. ${ }^{11,12}$

Didapatkan temuan efek samping berupa pusing, mual, mengantuk, dan juga menggigil. Efek samping ini terjadi lebih banyak pada kelompok tramadol-parasetamol 1 gram intravena bila dibandingkan dengan kelompok tramadol- ketorolak $30 \mathrm{mg}$ intravena. Namun, secara statistik efek samping yang timbul pada kedua kelompok tidak berbeda bermakna.

\section{Simpulan}

Pemberian kombinasi tramadol parasetamol $1 \mathrm{~g}$ intravena sebanding dengan tramadol ketorolak 30 mg intravena terhadap nilai NRS dan kebutuhan analgetik opioid pascabedah histerektomi abdominal.

\section{Daftar Pustaka}

1. Macres SM, Moore PG, Fishman SSM. Acute pain management. Dalam: Barash PGCB, Stoelting RK, Cahalan MK, Stock $\mathrm{MC}$, penyunting. Clinical anesthesia. Edisi ke-6. Philadelphia: Lippincott Williams \& Wilkins; 2009. hlm. 1473-502. 
2. Marsaban AHM, Ma'as EM, Bagianto H. Ilmu pengetahuan dasar. Dalam: Chandra $\mathrm{S}$, penyunting. Panduan tatalaksana nyeri perioperatif. Edisi ke-1. Jakarta: PP IDSAI; 2009. hlm. 1-22.

3. Morgan GE, Mikhail MS, Murray MJ. Pain management. Dalam: Morgan GE, penyunting. Clinical anesthesiology. Edisi ke-4. New York: McGraw-Hill Companies, Inc; 2006. hlm. 359-411.

4. Yap SOW, Husain A, Kapp DS, Teng NT, Schmiesing C. Gynecologic oncology. Dalam: Jaffe RA, Samuels SI, penyunting. Anesthesiologist's manual of surgical procedures. Edisi ke-4. Philadelphia: Lippincott Williams \& Wilkins; 2009. hlm. 745-83.

5. White P. The changing role of non-opioid analgesic techniques in the management of postoperative pain. Anesth Analg. 2005;101:S5-22.

6. Hurley RW, WU CL. Acute postoperative pain. Dalam: Miller RD, penyunting. Miller's anesthesia. Edisi ke-6. Philadelphia: Elsevier Churchill Livingstone; 2005. hlm.
2729-51.

7. Gandhi K, Viscusi E. Multimodal pain management techniques in hip and knee arthroplasty. J NYSORA. 2009;13:1-10.

8. Reeves RR BR. Tramadol: basic pharmacology and emerging concepts. Drugs Today. 2008;44(11):827-36.

9. Lee SY, Lee WH, Lee EH, Han KC, Ko YK. The effects of paracetamol, ketorolac, and paracetamol plus morphine on pain control after thyroidectomy. Korean J Pain. 2010;23(2):124-30.

10. Toussaint K, Yang XC, Zielinski MA, Reigle KL, Sacavage SD, Nagar S. What do we (not) know about how paracetamol (acetaminophen) works?. J Clin Pharm Ther. 2010;35:617-38.

11. Bertolini A1, Ferrari A, Ottani A, Guerzoni S, Tacchi R, Leone S. Paracetamol: new vistas of an old drug. CNS Drug Rev. 2006;12(3-4):250-75.

12. Ketorolac. 2011 [diunduh 22 Desember 2013]. Tersedia dari: http://www.drugs. $\mathrm{com} / \mathrm{mtm} /$ ketorolac.html?printable=1; 